\title{
New Possible Earthquake Precursor and Initial Area for Satellite Monitoring
}

\author{
Atanas Vasilev ${ }^{1 *}$, Milen Tsekov ${ }^{2}$, Petar Petsinski ${ }^{1}$, Konstantin Gerilowski ${ }^{3}$, \\ Violeta Slabakova ${ }^{1}$, Dimitar Trukhchev ${ }^{4}$, Emil Botev ${ }^{5}$, Orlin Dimitrov ${ }^{1}$, Nikolai Dobrev $^{6}$ and \\ Dimitar Parlichev ${ }^{1}$
}

${ }^{1}$ Institute of Oceanology, Bulgarian Academy of Sciences, Varna, Bulgaria, ${ }^{2}$ Department of Meteorology and Geophysics, Faculty of Physics, Sofia University "St. Kliment Ohridski", Sofia, Bulgaria, ${ }^{3}$ Institute of Environmental Physics, University of Bremen, Bremen, Germany, ${ }^{4}$ Institute of Metal Science, equipment, and technologies with Center for Hydro- and -Aerodynamics "Acad. A. Balevski", Bulgarian Academy of Sciences, Varna, Bulgaria, ${ }^{5}$ National Institute of Geophysics, Geodesy and Geography, Bulgarian Academy of Sciences, Sofia, Bulgaria, ${ }^{6}$ Geological Institute, Bulgarian Academy of Sciences, Sofia, Bulgaria

OPEN ACCESS

Edited by:

Giovanni Martinelli,

National Institute of Geophysics and

Volcanology, Italy

Reviewed by:

Boyko Ranguelov, University of Mining and Geology

"Saint Ivan Rilski," Bulgaria

Luca Piroddi,

University of Cagliari, Italy

${ }^{*}$ Correspondence:

Atanas Vasilev

gasberg@mail.bg

Specialty section: This article was submitted to Solid Earth Geophysics, a section of the journal Frontiers in Earth Science

Received: 23 July 2020 Accepted: 28 December 2020 Published: 05 February 2021

Citation: Vasilev A, Tsekov M, Petsinski $P$ Gerilowski K, Slabakova V, Trukhchev D, Botev E, Dimitrov O, Dobrev N and Parlichev D (2021) New Possible Earthquake Precursor and Initial Area for Satellite Monitoring.

Front. Earth Sci. 8:586283. doi: 10.3389/feart.2020.586283
We propose a new possible earthquake precursor, a coastal water jet originating from shallow water gas seeps and colored by sediments, lifted from increased gas seeps emissions, preceding some earthquakes with offshore epicenters along the Bulgarian Black Sea coast and $M \geq 3$. The new possible earthquake precursor is site specific and may be observed in shallow coastal water regions where active faults are accompanied by hydrocarbon gas seeps. We point out to a region where it can be easily detected by direct observation and satellite remote sensing, Zelenka methane seeps (ZMS), near the Bulgarian Black Sea coast. The ZMS activation is related to the tectonic stress and fracturing preceding and accompanying the earthquakes in the Shabla-Kaliakra-Balchik region along the northern part of the Bulgarian Black Sea coast. We also propose an earthquake forecasting experiment, based on the following four hypotheses: 1) The change of the methane emission of shallow horizons is related to crustal strain changes preceding earthquakes in the region; 2) extreme change of the activity of underwater methane seepages appears immediately before nearby earthquakes; 3) shallow water methane seepages activity can be monitored by remote sensing; 4) satellites can register effects from an extreme increase in their emissions. The proposed earthquake forecasting experiment is based on the monitoring of methane seepages activity in the ZMS area by direct observation and remote sensing which may provide indication for preparatory earthquake activity preceding offshore earthquakes in the region.

Keywords: earthquake precursor, methane, seeps, active faults, satellite images, Black Sea

\section{INTRODUCTION}

Paradoxically, no one seismologist denies that possible earthquake precursors exist, but not everyone believes that short-term forecast is possible based on their study (Ouzounov et al., 2018). Recently, increasingly complex methods are proposed in earthquake prediction research. Unique and highprecision equipment is used to study precursory variations of radon (Sabbarese et al., 2020), groundwater level (Nakagawa et al., 2019), tilt (Zhou et al., 2019), electromagnetic field (Florios et al., 2020), thermal radiation (Wei et al., 2019), outgoing long waves (Xiong and Shen, 2017), electron content in the ionosphere (Kelley et al., 2017), etc. Despite these efforts reliable short-term earthquake prediction methods are still elusive and searching for new earthquake precursors continues. 
Recently, several studies demonstrated relationships between earthquake occurrences and underwater gas seepages (Nikonov, 2002; Gasperini et al., 2012; Fischer et al., 2013; Geersen et al., 2016; Géli et al., 2018; Bonini, 2019). It has been found that the great Maule earthquake in 2010 had caused new gas seepage off the coast of Chile (Geersen et al., 2016). Fischer et al. (2013) demonstrate an increase in the upward flux of gas-hydrate-derived methane after the strong 1945 Makran earthquake. Gasperini et al. (2012) demonstrate the correlation between tectonic structures and gas seepages at the seafloor along the North Anatolian Fault in the eastern Sea of Marmara and suggest that it is an interesting region for searching fluid exhalations as an earthquake precursor. Géli et al. (2018) find that aftershocks following the M 5.1 earthquake of July $25^{\text {th }}, 2011$, in the western Sea of Marmara, occur within a zone of gas overpressuring, further demonstrating relationships between seismic activity and gas dynamics along the North Anatolian Fault. Nikonov (2002) provides evidence for fire columns observed off the coast during the 1927 Crimea earthquakes probably related to self-ignition of underwater methane seepages. All these studies present evidence for coseismic and postseismic methane seepage changes or a correlation between tectonic faults and methane seepage sources. There are some papers relating gas seepage related precursory phenomena to seismic activity. Soter (1999) presents evidence for a number of precursory phenomena, including bubbling of the sea, observed prior to the M 6.2 Aigion, Greece earthquake, some of which may be considered as symptoms of gas venting. Khilyuk et al. (2000) also point out that prior to the Northridge, California earthquake of 1994 significant increase in the offshore hydrocarbon seepage has been observed but was attributed to a malfunction of the measuring device. To our knowledge, observed gas seepage related precursory phenomena have not been used as a testable tool for earthquake forecasting.

Here we propose a new possible site specific earthquake precursor (a coastal water jet originating from shallow water gas seeps and colored by sediments, lifted from increased gas seeps' emissions) and we point out a monitoring area, Zelenka methane seeps (ZMS), near the Bulgarian Black Sea coast where the new possible precursor is easily observed. We find an extreme increase in both the seeps' area and discharge 4 days before the strongest offshore earthquake near the Bulgarian Black Sea coast in recent decades (Md 4.7, August 5, 2009; Tsekov et al., 2019) occurring in a close proximity to the ZMS. We also find that the precursory jet with a diameter of $\sim 8 \mathrm{~km}$ is observed on a sequence of satellite images with a resolution of $250 \mathrm{~m}$ (NASA Earth Data, 2020). We further document and discuss the relation between methane seeps activity and seismic activity in the highly seismic offshore Black Sea region near cape Kaliakra by finding evidence for increased methane seepage activity preceding some $\mathrm{M} \geq 3$ earthquakes in the same region.

The new possible precursor is related to the common cause of earthquake precursors, the tectonic stress and the fluids properties in the Earth's crust. It is specific to coastal regions and may be important for earthquake prediction in such often densely populated regions where the population and infrastructure are threatened by both earthquakes (Géli et al., 2018) and tsunamis (Bryant, 2018).

We discuss the suitability of the Zelenka methane seeps area as an observation point to study the new possible earthquake precursor and the possibility to organize regular observations in the region providing information on the methane seeps activity not only as a possible earthquake precursor but also as a viable source of information on environmental change processes.

\section{MATERIALS AND METHODS}

\section{Black Sea: Properties and Seismic Activity}

The Black Sea is a semienclosed basin, characterized by strong stratification, the presence of oxygen-free water layer, mud volcanoes, freshwater springs, methane sources and gas hydrates $(\mathrm{GH})$, etc. The Black Sea deep water is the biggest anoxic methane and hydrogen sulfide reservoir of the world (Reeburgh et al., 1991) (87\% of the water volume). It is known that the first sample with natural GH was recovered in 1972 by a gravity corer in the Danube Fan (Yefremova and Zhizhchenko, 1974). A circum-Black Sea belt of gas flares marks the lateral boundary of the GH stability zone (Vassilev, 2006). The basin is almost aseismic during the last century. Seismic activity is restricted to the periphery of the basin. Seismic activity of the region may trigger earthquake tsunamis (Bryant, 2018), mud volcano eruptions, and coastal land and underwater landslides. There is a close geophysical and hydrodynamic connection between many of these processes. Some of them may be dangerous or even catastrophic, while others may have important practical applications.

The seismicity of the Black Sea increases toward the margins of the basin. The most active regions are offshore Bulgaria, Crimea, Georgia, and Turkey. The depths of the earthquake hypocenters are up to about $35 \mathrm{~km}$. Only few earthquakes are registered in the abyssal part of the basin. An unexpected result from CRIMEA project was that areas with mud volcanoes are completely aseismic (Vassilev et al., 2006), in contrast to the strong time and space correlations between mud volcanoes and earthquake epicenters in the Caspian Sea.

The focal mechanisms show primarily N-S compression. The westward motion of the Anatolian Plate and N-S deformation of the Caucasus take up most of the motion of the Arabian Plate and only $\sim 1 \mathrm{~mm}$ year $^{-1}$ is transmitted through the Pontides to compress the Black Sea in N-S direction (Kalafat, 2017). The two strongest earthquakes in our area are an exception with focal mechanisms with primarily E-W compression with some N-S component and oblique strike-slip faulting (Kalafat, 2017).

The available information on the Black Sea tsunami can be divided into two types: historical (which is descriptive) and a limited number of modern data records from tide gauge measurements. A summary analysis can be found in Dotsenko and Ingerov (2007). According to sea level measurements, the highest recorded Black Sea tsunami height is $0.52 \mathrm{~m}$, while visual estimates of tsunami height $\sim 1-2 \mathrm{~m}$ exist (Dotsenko and Ivanov, 2010).

\section{Bulgarian Coastal Gas Seeps}

About 50 areas with underwater gas seeps are identified near the Bulgarian Black Sea coast (Dimitrov, 2002). The gas is mainly methane (Dimitrov et al., 1979). The first documented underwater gas seeps are observed (Palii et al., 1951) at 


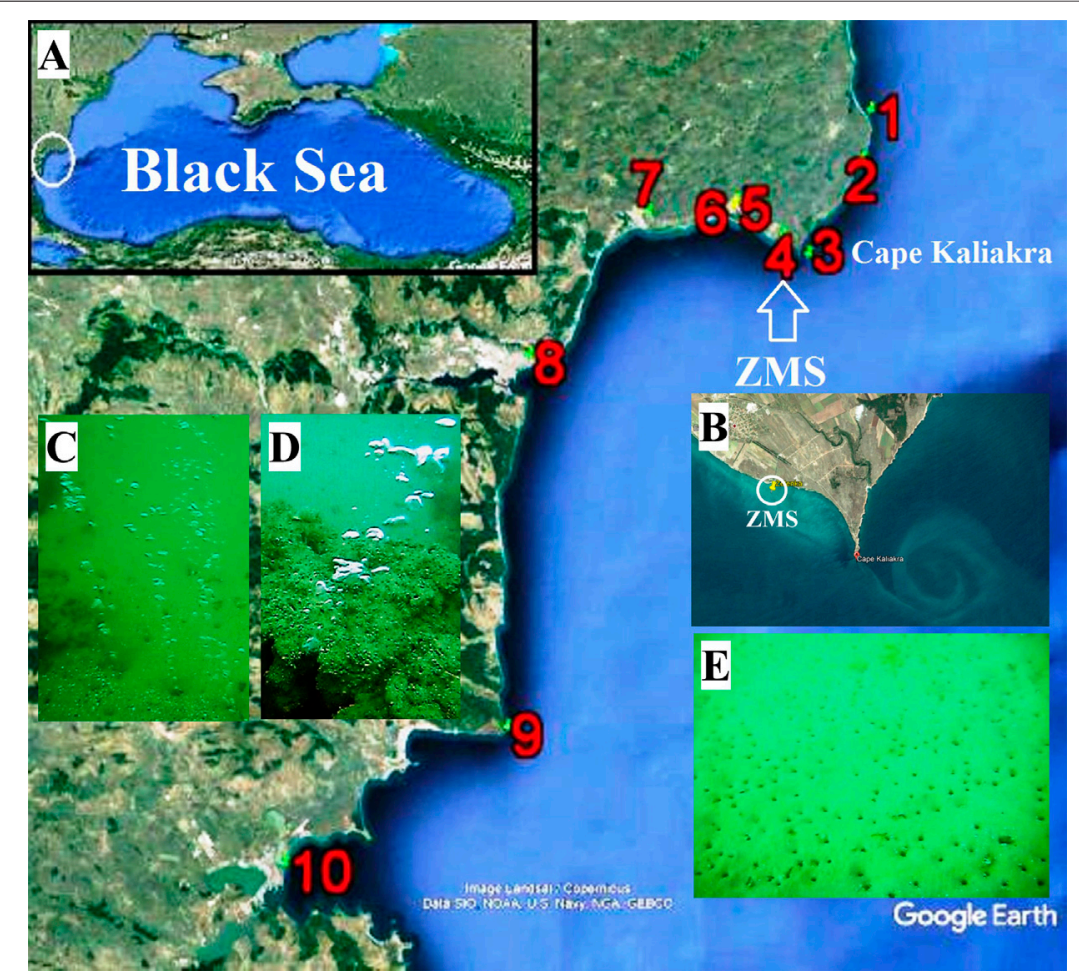

FIGURE 1 | (A) Black Sea (in the upper left corner) and the area of interest (enlarged). Numbers designate geographical locations discussed in the text: 1) cape Shabla, 2) Tyulenovo, 3) cape Kaliakra, 4) Zelenka, 5) cape Chirakman, 6) Town of Kavarna, 7) Town of Balchik, 8) City of Varna, 9) Cape Emine, 10) City of Bourgas (Google Earth ${ }^{\mathrm{TM}}$ ); (B) cape Kaliakra and ZMS (Google Earth ${ }^{\mathrm{TM}}$ ); (C) methane seeps from the seafloor covered by sand and clay aleurites; (D) ZMS outcrops of Sarmatian limestone; (E) photo of the ZMS seafloor with inactive microcraters at water depth $\sim 9 \mathrm{~m}$ from Sep. 10, 2009 , obtained 36 days after the Md = 4.7 earthquake (underwater photos K. Gerilowski).

Aladja Bank (between Varna and Balchik, see Figure 1). Later, underwater gas seeps areas along the Bulgarian coast zone are observed at Tsarevo, Rosen (Mandev et al., 1978), Kamchia, Rusalka, Shabla, and Tulenovo (Dimitrov et al., 1979).

\section{Zelenka Methane Seeps}

Intensive gas seeps from the seafloor are observed at least from a century in the area of the fisherman hut "Zelenka." The area, known as Zelenka methane seeps, is located $3 \mathrm{~km}$ to the west of cape Kaliakra (Figures 1A,B). According to the first investigations (Dimitrov et al., 1979): 1) the seepage area of $\sim 29,000 \mathrm{~m}^{2}$ is located $170-270 \mathrm{~m}$ of the coast and its size is $550 \times(25-100) \mathrm{m} ; 2)$ most of the seeps are at water depths $5-10 \mathrm{~m} ; 3)$ sand and clay aleurites with outcrops of Sarmatian limestones cover the seafloor (Figures 1C,D); 4) the gas is mainly methane (93-96\%) and nitrogen (4-5\%) and the rest is divided between $\mathrm{O}_{2}, \mathrm{CO}_{2}$, and $\mathrm{C}_{2} \mathrm{H}_{6} ; 5$ ) the discharge of a seep is $\leq 4 \mathrm{lmin}^{-1}$ and the ZMS annual discharge is $\sim 0.04 \mathrm{~km}^{3}$ year $^{-1}$ $\left(37.5 \times 10^{6} \mathrm{~m}^{3}\right.$ year $\left.^{-1}\right)$.

\section{Historical Earthquakes and Tsunamis in the Shabla-Kaliakra-Balchik Region}

Shabla-Kaliakra-Balchik region (43.0N-44.3N; 27.75E-30.0E) (Tsekov et al., 2019) where the methane seeps zone Zelenka is located is characterized by moderate seismic activity in recent decades. It is distributed on a multitude of intersecting onshore and offshore faults. In the past, several strong earthquakes hit the region. According to historical records, the settlements in the region suffered damage from earthquakes and even tsunamis (Papadopoulos et al., 2011; Oaie et al., 2016). In the first century BC, Strabo mentioned that the ancient Bizone (modern Kavarna, see Figure 1A) was destroyed in $64 \mathrm{BC}-19 \mathrm{AD}$ and the lobe part of cape Chirakman with the houses of the richest citizens sunk in the sea (Papadopoulos et al., 2011; Peev, 2016). Two strong historical earthquakes with not well-defined epicenters but possibly related to the Shabla-Kaliakra-Balchik zone occurred in $543 \mathrm{AD}$ and 1444 AD (Guidoboni et al., 1994; Ranguelov, 2008; Oaie et al., 2016).

The strongest regional earthquake in recent times occurred on March 31, 1901, 07:12:24 with an epicenter on an offshore fault near Port Balchik, $22 \mathrm{~km}$ west from Zelenka. The estimated parameters of the quake are $\mathrm{Mw} 7.2, \mathrm{MMI} \mathrm{X}$, and depth $14 \mathrm{~km}$. The quake generated widespread landslides and rockfalls along the shore.

The quality of the information about the seismic activity in the region improved significantly after 1986, several years after starting of operation of the Bulgarian National Seismic Network in 1980 (Botev et al., 2013; Tsekov et al., 2019). In the recent decades, information on the weak seismicity in the Shabla-Kaliakra-Balchik region is also available, with a magnitude of completeness Mc = 2,2 (Tsekov et al., 2019). 


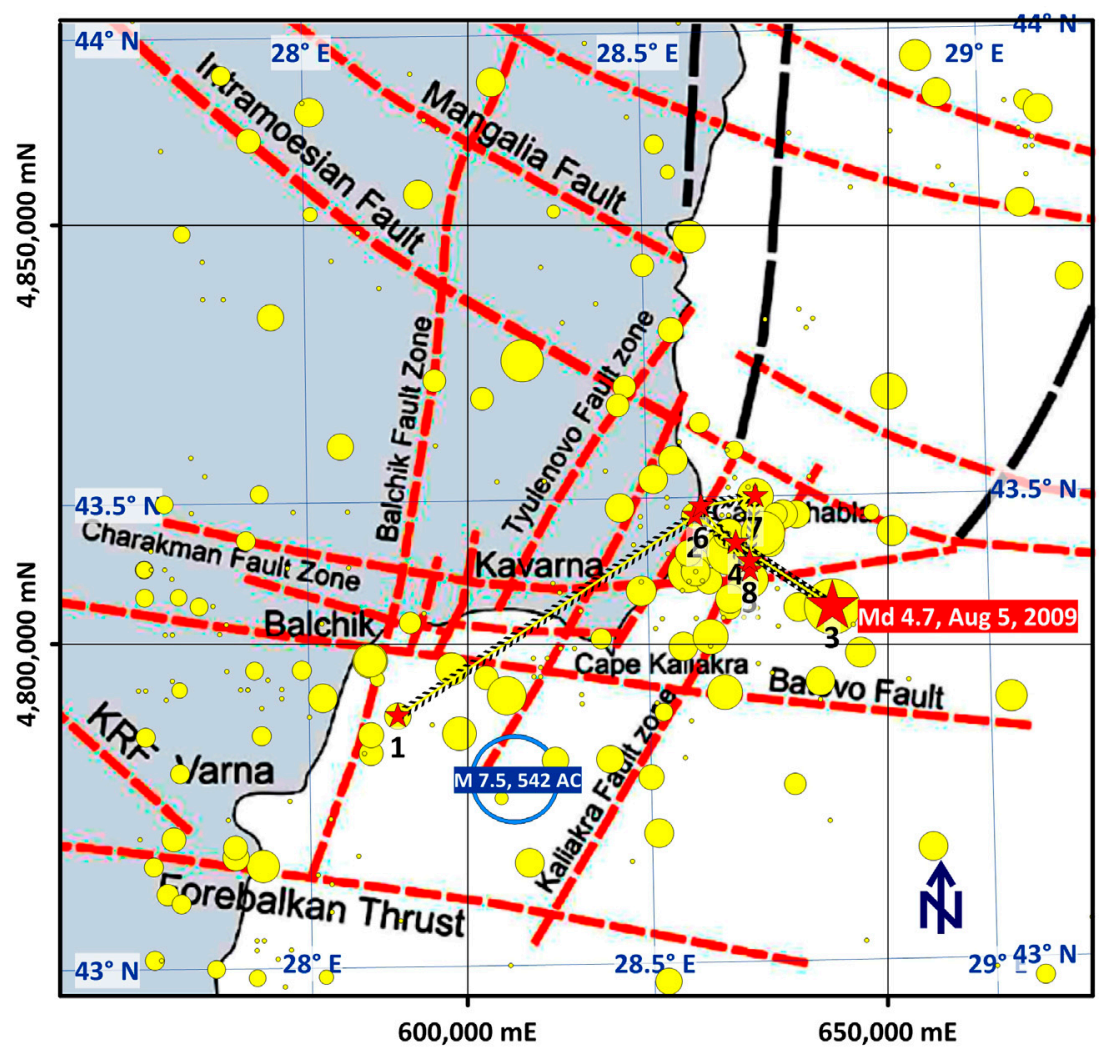

FIGURE 2 | The Shabla-Kaliakra-Balchik seismic region: main faults and registered earthquakes over the period 1986-2014 (after Oaie et al., 2016 and Tsekov et al., 2019). Yellow dots represent earthquake epicenters. With a red star is represented the strongest earthquake in the region over the period 1986-2014, occurring on 5 August, 2009, with Md 4.7. Numbers indicate this earthquake and its foreshocks and aftershocks in a chronological order.

\section{Data}

We use the following data in our analysis (provided as a supplement to this paper): 1) Data from the Bulgarian National Seismic Network about 198 seismic events occurring over the period 1986-2014 in the Shabla-Kaliakra-Balchik region (Supplementary Table S1), located in the NE part of Bulgaria and the adjacent part of the Black Sea $\left(43.0^{\circ}-44.3^{\circ} \mathrm{N}\right.$, $27.75^{\circ}-30.0^{\circ} \mathrm{E}$ ). The strongest earthquake in the region over the considered period: Western Black Sea; $27.5 \mathrm{~km}$ east of Zelenka; $43.38^{\circ} \mathrm{N}, 28.77^{\circ} \mathrm{E}$; depth $8 \mathrm{~km}$; Md 4.7; August 5, 2009, 07:49:00.3 (M4.7); 2) Global CMT (https://www.globalcmt.org; errors are from CMT inversion): $43.42 \pm 0.02^{\circ} \mathrm{N}, 28.60 \pm 0.02^{\circ} \mathrm{E}$; depth $=19$. $9 \pm 1.6$; half duration $=0.7$; centroid time minus hypocenter time: 1.5; moment tensor: Expo $=23,0.169,2.850,-3.020,-1.650,0$. $354,1.230 ; \mathrm{Mw}=5.0, \mathrm{Mb}=4.7, \mathrm{Ms}=0.0$, scalar moment $=3$. $59 \mathrm{e}+23$; fault plane 1: strike $=211$, dip $=65$, slip $=171$; fault plane 2 : strike $=305$, dip $=82$, slip $=26(200908050749$ A BLACK SEA $)$; 3) geophysical and geochemical data from the offshore methane seepages area Zelenka $\left(43.381^{\circ}-43.383^{\circ} \mathrm{N}, 28.426^{\circ}-28.431^{\circ} \mathrm{E} ; \sim 350\right.$ $\times 200 \mathrm{~m}$ ) including: (3.1) echosounder bathymetry and seafloor mosaic image from $800 \mathrm{kHz}$ side-scan sonar (Supplementary Images S1-S3); (3.2) main onshore and offshore faults locations: Zelenka is in the Charakman Fault Zone (Figure 2); (3.3) locations of 102 most active seepage groups providing evidence for migration pathways (Supplementary Image S1); (3.4) underwater videos and photos, starting at depths 9.4, 8.9, and $6.8 \mathrm{~m}$ showing the seafloor with the most active seepages and wide areas around them showing microcraters but without gas bubbles, indicating recent strong gas seepage activity (10 September 2009); Figure 1E (3.5) images obtained by the infrared camera for thermal analysis FLIR from the cliff, showing seepages registered on the sea surface as thermal anomalies (Supplementary Image S4); (3.6) results from gas content and sediment samples analyses; 4) Aqua EOS satellite images with resolution $250 \mathrm{~m}$ from sensor MODIS true color R $(700 \mathrm{~nm}), \mathrm{G}$ $(546.1 \mathrm{~nm})$, B $(435.8 \mathrm{~nm})$ over the period 01.08.2009-04.08.2009, showing the development of a light colored jet originating from Zelenka (Figure 3); 5) 16 Aqua EOS satellite images with resolution $250 \mathrm{~m}$ from sensor MODIS true color R (700 nm), G (546.1 nm), B $(435.8 \mathrm{~nm})$ for days with $\mathrm{M} \geq 3$ earthquakes in the Shabla-KaliakraBalchik region, as well as some preceding and following days (Supplementary Data Sheet S1); 6) Copernicus data "Black Sea high-resolution L4 sea surface temperature" (30.07-11.08.2009) and satellite data for sea surface temperature from NOAA 15, 17, 18, 19 and MetOp 2 for the period from 30 July to 13 August 2009 (MHPHI-RAS Marine Portal, 2020). 


\section{METHODS}

To identify possible methane seepage precursors the following analyses have been done: 1) ZMS area is surveyed with an echosounder and side-scan sonar as well as underwater video recording and infrared imaging of the sea surface with an infrared camera for thermal analysis from the cliff to obtain the temperature of the surface water: 1) lengths of the jets axes are determined from geo-referenced satellite images; 2 ) time of appearance of the jets is estimated. These results are supported by underwater visual observation of the sea floor and infrared observation of sea surface temperature changes above the active methane seeps region.

\section{RESULTS}

We find precursory changes in the activity of the shallow water Zelenka methane seeps (Black Sea, Bulgaria, Cape Kaliakra) related to the strongest earthquake in the Shabla-Kaliakra-Balchik region for recent decades (Tsekov et al., 2019) (Md 4.7, 5 August 2009, with an epicenter $\sim 27.5 \mathrm{~km}$ east from Zelenka).

Eight earthquakes with Md 2.3-4.7 and depths $8-20 \mathrm{~km}$ are registered during the period 2-8 August 2009 in the ShablaKaliakra-Balchik region as a foreshocks, mainshock, aftershocks series. Five of the quakes occurred on 5 August (7:49-15:56), starting with the mainshock with Md 4.7, which has been followed by four aftershocks later on the same day (Figure 3).

To obtain satellite imaging information about the region of interest during the foreshocks, main shock, aftershock series from 2 to 13 August 2009, we search the NASA archives (https://ladsweb. modaps.eosdis.nasa.gov). In the period 1-14 August 200915 satellite images of the ZMS area are available. Four of these satellite images registered brightly colored jets in the area of ZMS during the 4 days preceding the 5 August 2009 mainshock. Figure 3 shows the three images with highest quality. Table 1 summarizes the times of the satellite images and the lengths of the jet axes. Unfortunately, due to the poor quality of the images the errors in the axes length determination are significant (Figure 3; Table 1).

Four days before the offshore M4.7 earthquake from 5 August 2009 , the area with active methane seepages, located $27.5 \mathrm{~km}$ from the epicenter, increases 3-5 times. This estimation is based on the size of the area with microcraters but without seeps on the seafloor observed by the diver Dr. K. Gerilowski 36 days after the earthquake (Figure 1E). It indicates an extreme increase of methane emissions from the ZMS, which is further confirmed by the observed contrast jets in the satellite images (Figure 3).

Our working hypothesis is that upward gas flow lifts sediments from the sea floor, which may create observable sea surface temperature anomalies. Infrared camera observations show a temperature anomaly on the sea surface $\leq 0.5^{\circ} \mathrm{C}$ on a background temperature of $6.5^{\circ} \mathrm{C}$ in calm weather above the active seeps area, thus further confirming the extreme methane seepage activation.

The M4.7 offshore earthquake is preceded by two probable foreshocks (2 and 4 August 2009) and followed by several aftershocks, five of them in the period 5-8 August 2009. August 4th, $2009 \mathrm{Md}=2.3$ earthquake is identified as a foreshock according to the Gardner and Knopoff (1974) window criteria (Tsekov et al., 2019). August 2nd, 2009 Md = 2.3 earthquake is just outside Gardner and Knopoff (1974) spacetime window and formally it is not a foreshock according to their criteria. However, it occurs offshore, on the Batovo fault, which intersects the Kaliakra fault where the mainshock occurred and probably is part of the preparation process and thus may be considered as a distant foreshock. The proposed new possible precursor appears just a day before the first earthquake of the series (the distant foreshock). The epicenter of the second foreshock is near the coast, south of cape Shabla. It is followed by the 5 August Md4.7 main earthquake in the series, occurring offshore on the Kaliakra fault. It is interesting that the ZMS area is just in the line which connects the foreshocks epicenters and almost in its middle. The coincidence between the increased methane seeps activity and the occurrence of foreshocks is a strong suggestion that the methane seeps activity reflects the preparation process of the following earthquake and thus it may be considered as a possible earthquake precursor.

To study further the possible relation between surge in methane seepage activity and the seismic activity in the Shabla-Kaliakra-Balchik region we search satellite images for evidence of precursory or coseismic methane seepage activation prior to all regional earthquakes with $M \geq 3$. There are 11 such quakes over the period 1986-2014, excluding the $M \geq 3$ foreshocks and aftershocks as well as the already considered Md 4.7 earthquake of 5 August 2009. The epicenters of 3 of these 11 quakes are close to the shore but inland. No precursory or coseismic methane seeps activation is identified on satellite images for these 3 quakes. The remaining 8 earthquakes have offshore epicenters. Four of these are preceded by methane seepage surge identified on satellite images. Four days prior to the $\mathrm{Md}$ 3.8 earthquake of 30 November 2009 wide low-contrast colored jet indicating methane seepage activation is observed. A day prior to the Md 3.1 earthquake of 22 April 2011 contrast colored jet is observed. The jet enlarges the following day, hours before the quake. The proposed new possible earthquake precursor is also identified hours prior to the $\mathrm{Md} 3.7$ earthquake of 3 December 2012 and a day prior to the Md 3.2 earthquake of 6 February 2013.

We also checked for the new possible precursor 33 Google Earth images of the study area for periods without earthquakes and we found none, which suggests that the new possible precursor is not a common event. Thus, the probability that it occurs by chance hours/days before the corresponding earthquakes is low.

\section{DISCUSSION}

The area of ZMS is appropriate for organizing an observation experiment and monitoring of the new possible precursor, 

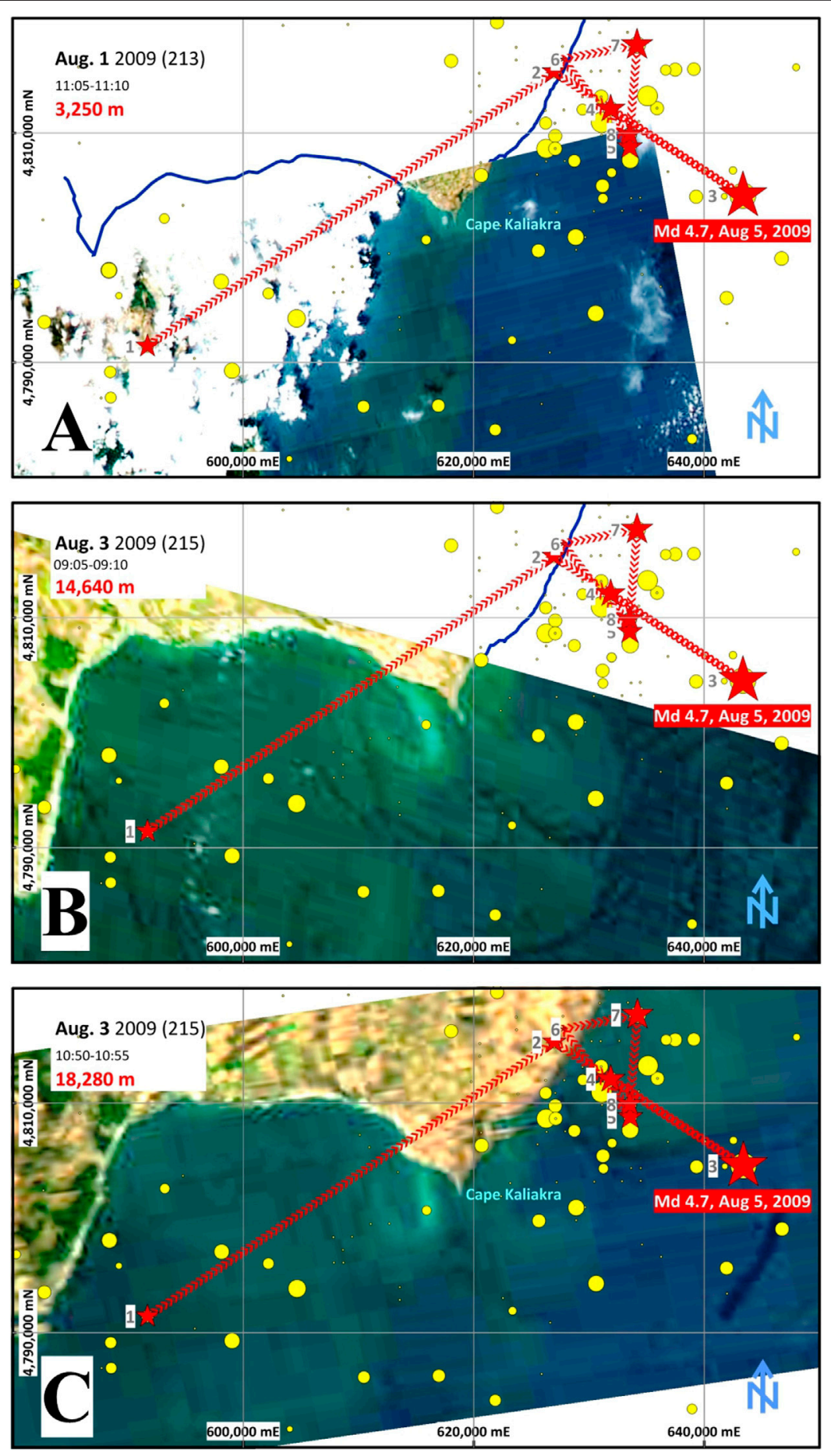

FIGURE 3 | Satellite images from the period 1 to 3 August with superimposed earthquake epicenters. Indicated are the dates of image generation and the lengths of the new possible precursor, the colored jets.

because of the following: 1) the area is easily observable, being close to the coast. The water is shallow which allows gas bubbles to reach the sea surface making it easy to monitor seeps activity observing the surface; 2) fine-grained almost white sediments cover the seafloor and strong methane emission could lift them to the surface creating contrast colored jets. Thus, identification of extreme methane emissions is relatively easy; 3 ) there is proximity to active seismic zone which potentially influences 
TABLE 1 | Satellite images data.

\begin{tabular}{|c|c|c|c|c|c|}
\hline Image & Date/Time UTC & $\begin{array}{l}\text { Cloud length } \\
\text { (m) }\end{array}$ & Diff. & Current (m/s) & Note \\
\hline (A) & August 1, 2009 (213) 11:05-11:10 & 3,520 & & & Cloud in the air \\
\hline (B) & August 3, 2009 (215) 09:05-09:09:59 & 14,640 & $11,120 \mathrm{~m} \mathrm{165,600s}$ & 0.067 & GeoRef problem: Rotation \\
\hline (C) & August 3, 2009 (215) 10:50-10:55 & 18,280 & $3,640 \mathrm{~m} \mathrm{6,300} \mathrm{s}$ & 0.578 & Small rotation, 2 scans not pasted \\
\hline (D) & August 4, 2009 (216) 09:50-09:55 & 22,620 & $4,340 \mathrm{~m} 82,800 \mathrm{~s}$ & 0.052 & Bad image quality, Unreliable value \\
\hline
\end{tabular}

methane seepage activity in the ZMS area. According to our database for the period 1986-2014, 198 earthquakes are registered by the Bulgarian National Seismic Network (Tsekov et al., 2019) or the average number of earthquakes per year is about 7. Also, a large number of active faults have been found offshore, along the Bulgarian Black Sea coast (Genov, Dimitrov, 2003; Dimitrov and Genov, 2004; Dimitrov and Vasilev, 2016), close to the ZMS area. Most active is the Kaliakra deep fault zone, the eastern wing of which sinks relative to the western. It is a bundle of subparallel faults, well expressed in the relief of the bottom, which can be traced to the cape Emine, and perhaps even on the land southwest of the city of Bourgas (see Figure 1A). The earthquake hypocenters in this area are relatively shallow, with depths up to $15-30 \mathrm{~km}$.

Unfortunately, the proposed new possible precursor depends strongly on weather conditions. Storms could erase the microcraters on the seafloor produced by extreme methane emissions. Clouds and wind waves could mask the underwater jets and make their satellite registration impossible. To avoid the clouds dependence a drone may be used for remote monitoring in cloudy days.

On the other hand, studying the seismic activity in the ShablaKaliakra-Balchik region and possibly predicting some of the stronger regional earthquakes is of great importance. Earthquakes in the region pose significant hazard to the near coastal settlements (Ranguelov et al., 2011). Moreover, some regional earthquakes may trigger gravitational processes along the coast (landslides, rockfalls) increasing the earthquake risk.

We propose to organize monitoring of the activity of Zelenka methane seeps (ZMS) which may include 1) regular check of satellite images for possible detection of the new possible precursor; 2) drone observation with thermo- and $4 \mathrm{~K}$ cameras; 3) geophysical survey with a small motorboat, ROV, USV, and/or AUV for estimation of the emissions area and discharge. Survey equipment may include GPS, underwater camera, side-scan sonar, multibeam, and profiler and sampling devices for gas, water, and seabed sediments; 4) setup of an online observation system with underwater video and gas discharge measurements and observations with a thermocamera from the cliff.

We also note that shallow water seeps with effects on water surface could be not so shallow. The critical depth is proportional to the gas discharge. A result from CRIMEA project shows that bubbles from natural gas seeps in the north-western part of the Black Sea reach the atmosphere if originating from depths shallower than $70 \mathrm{~m}$. The rest of the deeper seeps are consumed from biological and chemical processes in the water volume.

\section{CONCLUSION}

This work proposes a new possible earthquake precursor, colored jets from lifted sea floor sediments triggered by extreme emissions of shallow water gas seeps. The new possible precursor is detected by satellite images with a resolution $250 \mathrm{~m}$ before a moderate offshore earthquake along the Bulgarian Black Sea coast. The precursor is observed $\sim 24$ hours before the first foreshock at a distance of $26.5 \mathrm{~km}$ from its epicenter and $\sim 4$ days before the main earthquake on 5 August 2009 at a distance of $27.5 \mathrm{~km}$ from its epicenter. It results from the abrupt increase of the emitting area of ZMS (3-5 times) and the gas discharge from the seeps. We find similar behavior prior to several $3 \leq \mathrm{M}<4$ earthquakes in the same region, with less pronounced colored jets detected by satellite images.

We note that this work provides only an initial case history in support of the proposed new possible earthquake precursor. To meet the strict IASPEI criteria for "significant" earthquake precursors (Wyss, 1991; Wyss, 1997; Wyss and Booth, 1997) it is necessary to have simultaneous long-term data on methane seeps activity and seismic activity in a given region, which is still not available. We also note that the time coincidence between the observed increase methane seeps activity and occurrence of foreshocks, which are one of the recognized "significant" earthquake precursors (Wyss, 1991; Wyss, 1997), suggests that the observed phenomenon may indeed be used as an earthquake precursor.

The new possible precursor is site specific. It may be used for predicting offshore seismic activity in shallow water coastal regions. Our results demonstrate the uncommonly suitable conditions for monitoring the possible earthquake related changes in methane seeps activity in the Zelenka methane seeps area, located $\sim 3 \mathrm{~km}$ western from cape Kaliakra, Black Sea. The shallow water column allows bubbles and temperature anomalies to be easily registered at the sea surface.

One of the main strengths of the proposed new possible earthquake precursor is that it can be detected and observed relatively easily by remote sensing methods. We demonstrated it for the ZMS area, along the Bulgarian Black Sea coast, but it is probably applicable to other shallow water offshore seismic active regions. Thus, it is suitable for organizing regular monitoring. We discussed possible organization of regular observations searching for the proposed new earthquake precursor.

In parallel with monitoring for the precursor, the observation instruments may provide information on the budget of greenhouse gases and their impact on climate change, bioproductivity, and biodiversity, as well as to carry out an inventory of coastal gas seeps areas providing additional opportunities for energy development of coastal communities. 


\section{DATA AVAILABILITY STATEMENT}

The raw data supporting the conclusions of this article will be made available by the authors, without undue reservation.

\section{AUTHOR CONTRIBUTIONS}

$\mathrm{AV}, \mathrm{EB}, \mathrm{MT}$, and ND designed the research projects. AV wrote the first variant of the manuscript. AV, PP, and KG acquired survey data. VS collected and interpreted the satellite images. DT analyzed sea currents. EB, MT, and AV analyzed earthquake data provided by EB. OD, ND, and DP collected information for sections "Introduction" and "Materials and Methods" All authors contributed to the article and approved the submitted version.

\section{FUNDING}

This work was partially supported by Bulgarian Fund "Scientific Investigation" contracts: 1) KP-06-OPR04/7, 18.12.2018 GEOHydrate: Geothermal evolution of marine gas

\section{REFERENCES}

Bonini, M. (2019). Seismic loading of fault-controlled fluid seepage systems by great subduction earthquakes. Sci. Rep. 9 (1), 11332. doi:10.1038/s41598-01947686-4

Botev, E., Solakov, D., and Christoskov, L. (2013). On the monitoring of the seismic activity in the territory of Bulgaria and surroundings. Bulg. Geophys. J. 39, 59-69.

Bryant, E. (2018). Tsunami: the underrated hazard. Berlin, Heidelberg: Springer.

Dimitrov, L. (2002). Contribution to atmospheric methane by natural seepages on the Bulgarian continental shelf. Continent. Shelf Res. 22, 2429-2442. doi:10. 1016/s0278-4343(02)00055-9

Dimitrov, O., and Genov, I. (2004). Active faults in the south-eastern part of the moesian Plate and the lower-kamchia drop, C. R. Acad. Bulg. Sci. 57 (6), 83-88

Dimitrov, O., and Vassilev, A. (2016). Comprehensive analysis of data from geophysical studies in the western Black Sea. C. R. Acad. Bulg. Sci. 69 (10), 1333-1340.

Dimitrov, P., Dachev, V., Niklov, H., and Parlichev, D. (1979). Natural gas seepages in the offshore area of Balchik Bay. Oceanology BAS. 4, 43-49. (in Bulgarian)

Dotsenko, S., and Ingerov, A. (2007). Characteristics of tsunami waves in the Black Sea according to the data of measurements. J. Phys. Oceanogr. 17, 17-28. doi:10. 1007/s11110-007-0002-z

Dotsenko, S., and Ivanov, V. (2010). Natural disasters in the Azov-Black Sea region. Sevastopol: MHI. in Russian.

Fischer, D., Mogollon, J. M., Strasser, M., Pape, T., Bohrmann, G., Fekete, N., et al. (2013). Subduction zone earthquake as potential trigger of submarine hydrocarbon seepage. Nat. Geosci. 6, 647-651. doi:10.1038/ngeo1886

Florios, K., Contopoulos, I., and Christofilakis, V. (2020). Pre-seismic electromagnetic perturbations in two earthquakes in northern Greece. Pure Appl. Geophys. 177, 787-799. doi:10.1007/s00024-019-02362-6

Géli, L., Henry, P., Grall, C., Tary, J. B., Lomax, A., and Batsi, E. E. (2018). Gas and seismicity within the Istanbul seismic gap. Sci. Rep. 8, 6819-6911. doi:10.1038/ s41598-018-23536-7

Gardner, J. K., and Knopoff, L. (1974). Is the sequence of earthquakes in Southern California, with aftershocks removed, Poissonian?. Bull. Seismol. Soc. Am. 64, 1363-1367.

Gasperini, L., Polonia, A., Del Bianco, F., Etiope, G., Marinaro, G., Favali, P., et al. (2012). Gas seepage and seismogenic structures along the north Anatolian Fault in the eastern Sea of Marmara. G-cubed 13, 1-19. doi:10.1029/2012GC004190 hydrate deposits, Danube paleodelta, Black Sea; 2) DN14/1, 11.12.2017 GEOAPREQ: Geophysical fields' anomalies preceding earthquakes in Balkan region and National Science Program "Environmental Protection and Reduction of Risks of Adverse Events and Natural Disasters," approved by the Resolution of the Council of Ministers No. 577/17.08.2018 and supported by the Ministry of Education and Science (MES) of Bulgaria (Agreement No. D01-322/18.12.2019).

\section{ACKNOWLEDGMENTS}

The authors would like to thank all the reviewers for their help in improving the paper.

\section{SUPPLEMENTARY MATERIAL}

The Supplementary Material for this article can be found online at: https://www.frontiersin.org/articles/10.3389/feart.2020.586283/ full\#supplementary-material.

Geersen, J., Scholz, F., Linke, P., Schmidt, M., Lange, D., Behrmann, J., et al. (2016). Fault zone controlled seafloor methane seepage in the rupture area of the 2010 Maule Earthquake, Central Chile. Geochem. Geophys. Geosyst. 17, 4802-4813. doi:10.1002/2016GC006498

Genov, I., and Dimitrov, O. (2003). Faults and fault activity determined on the basis of seismic stratigraphy in the region east from the west Ahtopol Rise - southern Bulgarian Black Sea shelf. C. R. Acad. Bulg. Sci. 56, 71-76.

Guidoboni, E., Comastri, A., and Traina, G. (1994). Catalogue of ancient earthquakes in the mediterranean area up to the 10th century. Rome: Pub. Ist. Naz. Geofis. Vulcanol.

Kalafat, D. (2017). Seismicity and tectonics of the Black Sea. Int. J. Earth Sci. Geophys. 3, 011. doi:10.35840/2631-5033/1811

Kelley, M. C., Swartz, W. E., and Heki, K. (2017). Apparent ionospheric total electron content variations prior to major earthquakes due to electric fields created by tectonic stresses. J. Geophys. Res. Space Phys. 122, 6689-6695. doi:10. 1002/2016ja023601

Khilyuk, L. F., Chillingar, G. V., Robertson, J. O, Jr., and Endres, B. (2000). Gas migration. Events preceding earthquakes. Houston, TX: Gulf Publishing Company.

Mandev, P., Markova, K., and Kakacheva, V. (1978). Oil and gas manifestations along the Black Sea coast in the Burgas region. J. Petrol. Coal Geol. 8, 3-23.(in Bulgarian)

MHPHI-RAS Marine Portal. Black Sea archive (2020). (in Russian) Available at: https://ladsweb.modaps.eosdis.nasa.gov (Accessed July 22, 2020).

Nakagawa, K., Yu, Z.-Q., Berndtsson, R., and Kagabu, M. (2019). Analysis of earthquake-induced groundwater level change using self-organizing maps. Env. Earth Sci. 78, 445-455. doi:10.1007/s12665-019-8473-z

NASA Earth Data (2020). Available at: https://ladsweb.modaps.eosdis.nasa.gov (Accessed July 22, 2020).

Nikonov, A. A. (2002). Crimean earthquake in 1927. Unknown phenomena at sea. Priroda 9, 13-20.(in Russian)

Oaie, G., Seghedi, A., and Radulescu, V. (2016). Natural marine hazards in the Black Sea and the system of their monitoring and real-time warning. Geo-EcoMarina 22, 5-28. doi:10.5281/zenodo.889593

Ouzounov, D., Pulinets, S., Hattori, K., and Taylor, P. (2018). Pre-earthquake processes: a multi-disciplinary approach to earthquake prediction studies. Hoboken, NJ: Wiley(AGU).

Palii, A., Gelev, S., and Yankov, K. (1951). Geological framework and oil and gas perspectives of the Varna region: Open field work report. Sofia: National Geofond 
Papadopoulos, G., Diakogianni, G., Fokaefs, A., and Ranguelov, B. (2011). Tsunami hazard in the Black Sea and the azov sea: a new tsunami catalogue. Nat. Hazards Earth Syst. Sci. 11, 945-963. doi:10.5194/nhess-11-945-2011

Peev, P. (2016). Using archaeological data to infer past relative sea-level positions along the Bulgarian coast of the Black Sea. Méditerranée 126, 17-24. doi:10. 4000/mediterranee.8171

Ranguelov, B., Radichev, R., Dimovsky, S., Oaie, G., Dimitriu, R., and Diaconescu, M. (2011). Marinegeohazards project-key core elements of the early warning system in the Black Sea. Ann. MঊG University, Part I, Geol. Geophys. 54, 177-182.

Ranguelov, B. (2008). Tsunamis in the Black Sea and some recent investigations: natural hazards in the marine area. Bucharest, Romania: International Symopsium, 21-23.

Reeburgh, W. S., Ward, B. B., Whalen, S. C., Sandbeck, K. A., Kilpatrickt, K. A., and Kerkhof, L. J. (1991). Black Sea methane geochemistry. Deep Sea Res. Part A. Oceanographic Research Papers. 38, S1189-S1210. doi:10.1016/s0198-0149(10)80030-5

Roca, S. (1999). Macroscopic seismic anomalies and submarine pockmarks in the Corinth Patras rift, Greece. Tectonophysics 308, 275-290. doi:10.1016/S00401951(99)00090-6

Sabbarese, C., Ambrosino, F., Chiodini, G., Giudicepietro, F., and Macedonio, G. (2020). Continuous radon monitoring during seven years of volcanic unrest at Campi Flegrei caldera (Italy). Sci. Rep. 10, 9551-9610. doi:10.1038/s41598-020-66590-w

Tsekov, M., Botev, E., Dimova, L., and Raykova, R. (2019). Seismicity of the ShablaKaliakra-Balchik region over the period 1986-2014. Balkan Geoph. Soc. 2019, 1-5. doi:10.3997/2214-4609.201902652

Vassilev, A., Botev, E., and Hristova, R. (2006). Dvurechenskii mud volcano, Black Sea: long term activity from sedimentation, seismicity and tsunami data. C. $R$. Acad. Bulg. Sci. 59, 1181-1186.

Vassilev, A. (2006). Optimistic and pessimistic model assessments of the Black Sea gas hydrates. C. R. Acad. Bulg. Sci. 59, 543-550.

Wei, C., Lu, X., Zhang, Y., Guo, Y., and Wang, Y. (2019). A time-frequency analysis of the thermal radiation background anomalies caused by large earthquakes: a case study of the wenchuan 8.0 earthquake. Adv. Space Res. 65, 435-445. doi:10. 1016/j.asr.2019.09.019

Wyss, M., and Booth, D. (1997). The IASPEI procedure for the evaluation of earthquake precursors. Geophys. J. Int. 131, 423-424. doi:10.1111/j.1365-246X.1997.tb06587.x

Wyss, M. (1991). Evaluation of proposed earthquake precursors. Washington, DC: American Geophysical Union.

Wyss, M. (1997). Second round of evaluation of proposed earthquake precursors. Pure Appl. Geophys. 149, 3-16. doi:10.1007/BF00945158

Xiong, P., and Shen, X. (2017). Outgoing longwave radiation anomalies analysis associated with different types of seismic activity. Adv. Space Res. 59, 1408-1415. doi:10.1016/j.asr.2016.12.011

Yefremova, A. G., and Zhizhchenko, B. P. (1974). Occurrence of crystal hydrates of gases in sediments of modern marine basins. Dokl. Akad. Nauk SSSR, Earth Sci. Sect. 214, 1179-1181.

Zhou, C., Zeng, X., Wang, Q., Liu, W., and Wang, C. (2019). Rotational motions of the Ms 7.0 Jiuzhaigou earthquake with ground tilt data. Sci. China Earth Sci. 62, 832-842. doi:10.1007/s11430-018-9320-3

Conflict of Interest: The authors declare that the research was conducted in the absence of any commercial or financial relationships that could be construed as a potential conflict of interest.

Copyright (C) 2021 Vasilev, Tsekov, Petsinski, Gerilowski, Slabakova, Trukhchev, Botev, Dimitrov, Dobrev and Parlichev. This is an open-access article distributed under the terms of the Creative Commons Attribution License (CC BY). The use, distribution or reproduction in other forums is permitted, provided the original author(s) and the copyright owner(s) are credited and that the original publication in this journal is cited, in accordance with accepted academic practice. No use, distribution or reproduction is permitted which does not comply with these terms. 